GAPP, número 24, noviembre de 2020

Sección: ESTUDIOS

Recibido: 17-09-2019

Modificado: 27-03-2020

Aceptado: 27-03-2020

DOI: https://doi.org/10.24965/gapp.i24.10732

Páginas: 86-105

\title{
Transformaciones normativas recientes en el derecho a la seguridad social de las personas con discapacidad en Argentina
}

\section{Legal transformations in Social Security entitlements for people with disabilities in Argentina}

\author{
Mauricio Mareño Sempertegui \\ Universidad Nacional de Córdoba (Argentina) \\ ORCID: https://orcid.org/0000-0003-0353-2144 \\ mauriciomareno@gmail.com
}

\section{NOTA BIOGRÁFICA}

Licenciado en Trabajo Social y tesista en Maestría en Ciencias Sociales con mención en Políticas Sociales de la Facultad de Ciencias Sociales, Universidad Nacional de Córdoba (UNC). Docente de la Facultad de Ciencias Sociales. UNC. Miembro investigador del proyecto: "Regresividad de la seguridad social en Argentina: transformaciones recientes en la institucionalidad bienestarista". Proyecto CONSOLIDAR III, SECyT, UNC (2018-2021).

Nora Britos

Universidad Nacional de Córdoba (Argentina)

noravbritos@gmail.com

\section{NOTA BIOGRÁFICA}

Doctora en Ciencia Política por el Centro de Estudios Avanzados de la Facultad de Ciencias Sociales, UNC. Docente investigadora, profesora titular en la cátedra "Políticas Sociales del Estado" de la Facultad de Ciencias Sociales, UNC. Directora del proyecto: "Regresividad de la seguridad social en Argentina: transformaciones recientes en la institucionalidad bienestarista". Proyecto CONSOLIDAR III, SECyT, UNC (2018-2021).

\section{RESUMEN}

Este trabajo tiene como objetivo examinar las transformaciones acaecidas en el derecho a la seguridad social de las personas con discapacidad en Argentina, focalizando la mirada en la política de pensiones no contributivas por invalidez entre los años 2003 y 2019. A partir del análisis del marco normativo, se analizan las medidas tomadas por el Estado en dos períodos. Por un lado, el período 2003-2015, caracterizado por la expansión de la cobertura que supuso una mejora progresiva en el derecho a la seguridad social para esta población, mejora que presentó escasa institucionalidad ya que no fue el resultado de la derogación de una normativa anticonvencional (Decreto Reglamentario N 432/1997). Por el otro, el período 2016-2019 en el que a partir de la adopción de una serie de medidas regresivas, tanto a nivel normativo como en los resultados de la política de pensiones por invalidez, se ejecuta una masiva suspensión y baja de prestaciones, restringiéndose así el derecho a la seguridad social para este grupo poblacional. Se señala que la no derogación de una normativa nacional que transgrede estándares internacionales de derechos humanos, constituyó un acto de omisión por parte de los gobiernos de los dos períodos analizados. 
GAPP. Nueva Época - N. ${ }^{\circ}$ 24, noviembre 2020 - ISSN: 1989-8991 - DOI: https://doi.org/10.24965/gapp.i24.10732 - [Págs. 86-105]

Transformaciones normativas recientes en el derecho a la seguridad social de las personas con discapacidad en Argentina

Mauricio Mareño Sempertegui / Nora Britos

\title{
PALABRAS CLAVE
}

Derecho a la seguridad social; pensiones no contributivas por invalidez; discapacidad; regresividad normativa; regresividad de resultados.

\begin{abstract}
The objective of this work is to examine the transformations that have taken place in the right to social security for people with disabilities in Argentina, focusing on the policy of non-contributory disability pensions between 2003 and 2019. From the analysis of the normative framework, the measures taken by the State in two periods are analyzed. On the one hand, the period 2003-2015, characterized by the expansion of coverage that meant a progressive improvement in the right to social security for this population, an improvement that presented little institutionality since it was not the result of the repeal of a normative anticonventional (Regulatory Decree No. 432/1997). On the other hand, the period 2016-2019 in which, from the adoption of a series of regressive measures, both at the normative level and in the results of the disability pension policy, a massive suspension and reduction of benefits is carried out. Thus restricting the right to social security for this populational group. It is pointed out that the non-derogation of a national normative that transgresses international human rights standards, constituted an act of omission by the governments of the two periods analyzed.
\end{abstract}

\section{KEYWORDS}

The right to social security; non-contributory pensions for disability; disability; normative regressivity; regressivity of results.

\section{SUMARIO}

INTRODUCCIÓN. 1. BREVE PRESENTACIÓN DE LAS PENSIONES POR INVALIDEZ EN EL MARCO DE LAS PENSIONES NO CONTRIBUTIVAS ASISTENCIALES EN ARGENTINA. 2. PERÍODO 20032015. ADECUACIÓN FÁCTICA DE LAS CONDICIONES DE ACCESO. EXPANSIÓN DE LA COBERTURA Y RECONOCIMIENTO DEL DERECHO A LA SEGURIDAD SOCIAL. 2.1. AMPLIACIÓN DEL DERECHO A LA SEGURIDAD SOCIAL EN UN MARCO DE ESCASA INSTITUCIONALIDAD. 3. PERÍODO 2016-2019. ÉPOCA DE TRANSFORMACIONES REGRESIVAS EN LAS NORMAS JURÍDICAS Y EN LOS RESULTADOS DE LA POLÍTICA DE PENSIONES NO CONTRIBUTIVAS. 3.1. REGRESIVIDAD NORMATIVOJURÍDICA. CENTRALIZACIÓN Y COMBATE CONTRA EL (PRESUNTO) FRAUDE. 3.2. REGRESIVIDAD DE RESULTADOS. INTERPRETACIÓN TAXATIVA DE LA NORMATIVA Y COMPULSIVA BAJA-SUSPENSIÓN DE PENSIONES POR INVALIDEZ. 3.3. REACCIÓN ORGANIZADA A LOS RETROCESOS EN EL DERECHO A LA SEGURIDAD SOCIAL: LA RED POR LOS DERECHOS DE LAS PERSONAS CON DISCAPACIDAD (REDI). ALGUNAS CONCLUSIONES. REFERENCIAS BIBLIOGRÁFICAS.

\section{INTRODUCCIÓN}

Uno de los componentes más relevantes de la intervención social del Estado lo constituye el núcleo de la seguridad social. Históricamente, este núcleo estuvo dirigido a la protección de los trabajadores asalariados (y sus dependientes) ante contingencias que les impidieran mantener sus ingresos a través de su actividad laboral. Como indican la OIT (OIT, 2002) y el Comité de Derechos Económicos, Sociales y Culturales (CDESC, 2007), las ramas de la seguridad social son: atención de salud; enfermedad; vejez; desempleo; accidentes laborales; prestaciones familiares; maternidad; discapacidad; sobrevivientes y huérfanos. La historia de las políticas de seguridad social en Argentina es muy rica y compleja (Golbert y Roca, 2010; Bertranou et al., 2011). El derecho a la seguridad social fue reconocido en la Constitución Nacional de 1949; posteriormente fue incorporado como parte del artículo 14 bis de la Constitución Nacional de 1957 y la Constitución Nacional de 1994. En esta Constitución además se incorporaron Declaraciones, Convenciones y Pactos Internacionales de Derechos Humanos en el artículo 75 inciso 22 que explícitamente reconocen el derecho a la seguridad social y amplían el contenido y alcances de este derecho, entre ellos la Convención sobre los Derechos de las Personas con Discapacidad (Artículo 28) ${ }^{1}$.

1 Esta Convención es un instrumento internacional de derechos humanos de las Naciones Unidas destinado a proteger los derechos y la dignidad de este sector poblacional. Los países signatarios de la Convención tienen la obligación de promover, proteger 
La inclusión de los instrumentos internacionales también implica asumir las obligaciones estatales en materia de derechos económicos, sociales y culturales, entre las que destaca la obligación de adoptar progresivamente todas las medidas que conduzcan al goce de los derechos sociales para todos los habitantes, utilizando para ello el máximo de los recursos disponibles. La contracara de la obligación de progresividad es la prohibición de regresividad o retroceso. Dado que el Estado se obliga a mejorar la situación de estos derechos, simultáneamente asume la prohibición de reducir los niveles de protección de los derechos sociales vigentes, o de abolir los derechos ya existentes. En palabras del Comité de Derechos Económicos, Sociales y Culturales (Comité DESC) en la Observación General 3, «cualquier medida deliberadamente regresiva al respecto requerirá la más cuidadosa consideración y deberá ser justificada plenamente por referencia a la totalidad de los derechos previstos en el Pacto y en el contexto del aprovechamiento pleno del máximo de los recursos de que se dispone» (Comité DESC, Observación General 3, párrafo 9). Según Courtis (2006), la regresividad puede aplicarse a normas jurídicas o a los resultados de políticas públicas. En cuanto a la regresividad normativa o jurídica, «para determinar que una norma es regresiva, es necesario compararla con la norma que ésta ha modificado o sustituido, y evaluar si la norma posterior suprime, limita o restringe derechos o beneficios concedidos por la anterior» (Courtis, 2006; pág. 4). En lo que respecta a evaluar la regresividad de resultados en materia de políticas públicas, «la política pública desarrollada por el Estado es regresiva cuando sus resultados hayan empeorado en relación con los de un punto de partida temporalmente anterior elegido como parámetro» (Courtis, 2006; pág. 4).

Este artículo se refiere sólo a las Pensiones No Contributivas por invalidez, que forman parte de la seguridad social en Argentina y fueron creadas en 1970 a partir de la modificación del artículo 9 de la Ley 13.478 de 1948. Su reglamentación data de 1997 y puede caracterizarse como sumamente restrictiva y ajena a las obligaciones asumidas a través de la inclusión de los instrumentos de derechos humanos que reconocen el derecho a la seguridad social.

En ese sentido, se examina el lapso de tiempo comprendido entre los años 2003 y 2019, a partir de una investigación documental basada en la revisión y análisis de fuentes secundarias constituidas por el conjunto de normativas que regulan el acceso a las PNCA y, en particular, a las pensiones no contributivas por invalidez. Así, el corpus documental para esta investigación estuvo compuesto por leyes nacionales y sus modificaciones, decretos de necesidad y urgencia, decretos reglamentarios y resoluciones administrativas. En este marco, se analizan y comparan los cambios acontecidos en este intervalo de tiempo, en base en el estándar internacional de progresividad-prohibición de regresividad en materia de derechos humanos. El período de análisis se organiza en dos momentos: 2003-2015 y 2016-2019.

Se sostiene que durante los años 2003-2015, en los gobiernos de Néstor Kirchner y Cristina Fernández de Kirchner se produjo una adecuación fáctica de las condiciones de acceso al derecho, a los estándares que fueron introducidos a través de las Declaraciones, Convenciones y Pactos de Derechos Humanos -adecuación que representaría una mejora progresiva en la materia-, pero esta adecuación se realizó sin haberse modificado el decreto reglamentario de 1997. El gobierno de Mauricio Macri, a partir de diciembre de 2015, dejó de lado la adecuación fáctica precedente y basándose en el decreto de 1997, restringió (a través de la suspensión y baja masiva de prestaciones) el derecho a la seguridad social. Además, se produjeron modificaciones normativas y administrativas que se pueden caracterizar como regresivas. Así, en este trabajo se sostiene que las medidas adoptadas a partir de 2015 constituyen un caso en el que se produjo una sistemática regresión normativa y en los resultados de la política de pensiones no contributivas por invalidez.

El trabajo se organiza en cuatro apartados. En primer lugar, se presentan sucintamente las pensiones por invalidez al interior de las pensiones no contributivas asistenciales. Se repasa la ampliación de su cobertura desde su creación con la Ley $\mathrm{N}^{\circ} 13.478$ del año 1948, y se revisan sus condiciones de acceso atendiendo a la normativa que reglamenta esta Ley cuarenta y nueve años más tarde (Decreto Reglamentario $\mathrm{N}^{\circ} 432$ de 1997). En segundo término, se aborda el período 2003-2015, caracterizado por una expansión significativa de la cobertura, que supuso una mejora progresiva en el reconocimiento del derecho a la seguridad social de este colectivo poblacional, pero que no estuvo acompañada por modificaciones normativas que le otorguen institucionalidad.

En tercer lugar, se lleva a cabo un análisis de los retrocesos tanto normativos como en los resultados de la política de pensiones por invalidez, característicos del período 2016-2019. Se revisa, además, la conse-

y garantizar el pleno disfrute de los derechos humanos de estas personas y garantizar que gocen de plena igualdad ante la ley. La República Argentina adoptó esta Convención mediante la aprobación de la Ley 26.378 , el 21 de mayo de 2008 . Posteriormente a través de la Ley 27.044 de 2014 se le otorgó jerarquía constitucional. 
cuente contienda legal entre los titulares de prestaciones que fueron suspendidas o dadas de baja -representados por la Red por los Derechos de las Personas con Discapacidad-y el Estado nacional -representado por la Agencia Nacional de Discapacidad-.

Finalmente en las conclusiones, se subraya la relevancia de que los principios del derecho internacional de derechos humanos impacten en el derecho interno de los Estados nacionales. Se plantea que la no derogación de una legislación interna contraria a los principios del derecho internacional de derechos humanos, supuso un acto de omisión por parte de las gestiones de gobierno de los dos períodos examinados. Omisión que implicó la restricción del derecho a la seguridad social de las personas con discapacidad receptoras de pensiones por invalidez.

\section{BREVE PRESENTACIÓN DE LAS PENSIONES POR INVALIDEZ EN EL MARCO DE LAS PENSIONES NO CONTRIBUTIVAS ASISTENCIALES EN ARGENTINA}

La política de pensiones no contributivas (PNC) en Argentina presenta cuatro modalidades específicas: las pensiones destinadas a ex combatientes de Malvinas, las que son asignadas por un legislador nacional (también llamadas pensiones graciables), las comprendidas en Leyes Especiales y las pensiones no contributivas asistenciales (PNCA). Estas últimas, a su vez, contienen tres tipos diferentes de pensiones, a saber, las pensiones por vejez, las pensiones para madres con siete hijos o más y las pensiones por invalidez (CEPAL, 2017; Bertranou, Casalí y Cetrángolo, 2019; Mallardi y Fernández, 2019).

Las PNCA tienen su origen en 1948 a partir de la Ley $\mathrm{N}^{\circ} 13.478$, inicialmente concebidas para la vejez sin cobertura previsional, es decir, para «personas sin recursos propios, de sesenta años o más, no amparadas por un régimen de previsión». Décadas más tarde, específicamente en 1970, estas prestaciones extienden su cobertura a personas «imposibilitadas de trabajar», creándose así las pensiones por invalidez (Ley $\mathrm{N}^{\circ}$ 18.910/1970). Posteriormente a través de la Ley $\mathrm{N}^{\circ} 23.746$ de 1989, su cobertura se amplía una vez más, incorporando a las mujeres que tuviesen siete o más hijos, cualquiera fuese su edad y estado civil.

El artículo 9 de la Ley $N^{\circ} 13.478$ que origina las PNCA, y que establece sus destinatarios y las condiciones para percibirlas, se reglamenta cuarenta y nueve años más tarde de ser sancionada, a través del Decreto Reglamentario № 432 de 1997.

Como se observa, desde su creación en 1948 las PNCA han ido ampliando sus destinatarios. No obstante, algunas de las condiciones para acceder a ellas se han mantenido en el tiempo y otras se han ido sumando. En ese sentido, los requisitos ligados a la edad «sesenta o más años de edad», a la indigencia ${ }^{2}$ «no poseer bienes, ingresos ni recursos de otra naturaleza que permitan la subsistencia del solicitante y grupo conviviente» y a la ausencia de cobertura previsional «personas no amparadas por un régimen de previsión», permanecen desde la Ley $\mathrm{N}^{\circ} 13.478$.

En 1970 se incorpora una nueva condición biológica, además de la edad, esta vez referida a la «incapacidad para trabajar». Así, el nuevo sujeto de las PNCA será aquel que porte un déficit personal que lo exime legítimamente de la obligación de trabajar y de la obligación de aportar (obligación previsional), ya que se supone que este sujeto no está en condiciones de trabajar aunque quisiera. Diecinueve años después, en 1989, aparece la condición de acceso derivada de la maternidad y cuidado de siete hijos/as o más.

En la década del 90 del siglo XX, en un contexto de predominio de políticas asistenciales focalizadas y compensatorias contra la pobreza, las PNCA, y las PNC en general, fueron concebidas como un programa para la reducción de la pobreza en segmentos de la población que tradicionalmente han sido excluidos de la seguridad social (Bertranou y Grushka, 2002). En ese marco, se reglamentan las PNCA y las condiciones establecidas para percibirlas llevan a un extremo su carácter restrictivo, a tal punto que, como plantean AA.VV $(2012,2017)$ y Britos y Caro (2018), «desnaturalizan el derecho a la seguridad social» que debieran proteger. De este modo, el Decreto 432/1997, plantea la necesidad de unificar y actualizar las normativas respecto a las PNCA y constituye una reglamentación «extremadamente restrictiva» (Britos y Caro, 2018) ya que:

- Eleva la edad que habilita el acceso a las pensiones a la vejez. Se establece que los beneficiarios de esta prestación tengan como mínimo 70 años o más. Su ley de creación fijaba la edad de 60 años ${ }^{3}$.

2 Cabe destacar que este requisito se explicita formalmente en el texto de la Ley $\mathrm{N}^{\circ} 15.705$ de 1960 , que modifica el artículo $9^{\circ}$ de la Ley $\mathrm{N}^{\circ} 13.478$ 65 años.

3 Cabe señalar que la Ley $N^{\circ} 20.267$ de 1973, ya había elevado la edad mínima para el acceso a estas prestaciones de 60 a 
- Instituye la noción jurídica de incapacidad laboral total o permanente como criterio para la asignación de pensiones por invalidez. Esta incapacidad se interpreta como resultado de la invalidez (concebida como sinónimo de discapacidad) y se calcula en base a fundamentos y valores exclusivamente médicos, que determinarán la clase y el grado de ineptitud para el trabajo. Se establece «que la incapacidad es total cuando la invalidez produzca en la capacidad laborativa una disminución del SETENTA Y SEIS (76\%) o más» ${ }^{4}$.

- Lleva a un extremo «el estado de necesidad del peticionante», el cual debe equipararse a un estado de indigencia y desafiliación absoluta, o en términos de Castel (1991) al de indigencia desafiliada, es decir, una situación de doble desenganche con respecto al orden laboral (ausencia de trabajo y de ingresos) y a la inserción relacional (aislamiento relacional). En este marco, la reglamentación establece como condicionalidades:

«no poseer bienes, ingresos ni recursos que permitan la subsistencia; no estar amparado por un régimen de previsión, retiro o prestación no contributiva alguna; no tener parientes que estén obligados legalmente a proporcionarle alimentos o que teniéndolos, se encuentren impedidos para poder hacerlo; ni vivir con otros familiares bajo el amparo de entidades públicas o privadas en condiciones de asistirlo» (Decreto Reglamentario № 432,1997, pág. 2).

- Exige la acreditación de un mínimo de veinte (20) años de residencia continuada en el país a las personas extranjeras y de cinco (5) años a las personas naturalizadas, lo cual limita el acceso igualitario al derecho a la seguridad social. Este requerimiento no está previsto para los solicitantes nativos, a quienes únicamente se les exige la residencia en el país.

De esta manera, las condiciones restrictivas de acceso que establece este Decreto construyen el perfil de sujeto destinatario de las PNCA; sujeto que encarna la ineptitud biológica para el trabajo, la indigencia, la desafiliación y, si es extranjero, que resida de manera continuada en el país, por lo menos hace veinte (20) años.

Respecto a las pensiones por invalidez, el carácter restrictivo de sus condiciones de acceso suscitó algunas consecuencias en el perfil de estas prestaciones y, principalmente, en la población que las solicita.

Por un lado, se convirtieron en una prestación de escasa cobertura ya que las personas que efectivamente pueden cumplir con todos sus requisitos, constituyen un segmento muy reducido de la población. Analizaremos brevemente uno de esos requisitos a los fines de graficar esta afirmación: personas con discapacidad que acrediten como mínimo el $76 \%$ de incapacidad laboral según su certificado médico.

Según el Decreto 432/1997, únicamente aquellas personas con discapacidad que puedan demostrar que efectivamente poseen el $76 \%$ o más de incapacidad para trabajar, desde criterios netamente médicos, tendrían derecho a acceder a una pensión no contributiva por invalidez. Justificar ese porcentual de incapacidad para el desempeño laboral constituye el requisito sine qua non para acceder a esta prestación.

En ese marco, delimitar taxativamente un porcentual que, a partir de baremos médico-patológicos, expresaría el grado de ineptitud laboral necesario para obtener la pensión, supone, en primer término, adjudicar al saber médico la potestad de definir y decidir quiénes pueden percibirla y quiénes no. En términos de Foucault (1976: 27) «la autoridad médica aparece como una autoridad social que puede tomar decisiones en otros campos que no son esencialmente los de las enfermedades». Así, el acceso al derecho a la seguridad social de las personas con discapacidad se medicaliza. En segundo lugar, supone generar dos categorías de personas con discapacidad en base a criterios médico-administrativos, a saber, quienes merecen la prestación y quienes no, o en otros términos, aquellas personas con discapacidad que tienen derecho a la seguridad social y aquellas que no detentan ese derecho.

Este condicionante para el acceso a las pensiones no contributivas por invalidez, permite observar su carácter restrictivo que se reflejó en una baja cobertura. Lo cual constituyó una constante, al menos hasta el año $2003^{5}$.

4 Parece oportuno destacar que al momento de aprobarse el Decreto 432, la discapacidad se medía y determinaba según los criterios y estándares de la Clasificación Internacional de las Deficiencias, Discapacidades y Minusvalías (CIDDM) de la Organización Mundial de la Salud (OMS). Documento que representa la síntesis de las perspectivas biologicistas sobre la discapacidad del siglo XX, que la conciben como una condición individual, es decir, como el resultado de un déficit de origen exclusivamente biológico.

5 Como se verá más adelante, en ese año se inaugurará el período de mayor ampliación de su cobertura. 
Por otro lado, las condiciones restrictivas de acceso a estas prestaciones, fomentan la dependencia absoluta de las personas con discapacidad respecto a su familia de pertenencia. Es decir, supedita el derecho a gozar de los beneficios de la seguridad social a la disponibilidad de recursos provenientes del grupo familiar, lo cual conspira contra su autonomía, autodeterminación e independencia económica de la persona con discapacidad (RALS, CELS y REDI, 2003; AA.VV, 2017; Sorgi y Calderón, 2017). Como plantean AA.VV (2012: 75) «Manejarse en forma autónoma es concretar un modelo de vida independiente sin dependencias que coarten su libertad y, por ende, su posibilidad de desarrollo personal; todo lo cual está íntimamente ligado con su dignidad personal».

Por otra parte, instauran la incompatibilidad de la pensión no contributiva por invalidez con otras prestaciones y, sobre todo, con la inserción laboral de las personas con discapacidad. Resulta inquietante la pretensión de exclusividad que establecen sus condiciones de acceso, considerando lo magro que resulta su importe monetario, lo cual dificulta alcanzar un nivel de vida mínimamente satisfactorio en materia de vivienda, alimentación, y cuidados de la salud. A diciembre del 2019 el monto de la pensión no contributiva por invalidez era de $\$ 7.878$, el cual no alcanza a cubrir el $50 \%$ del Salario Mínimo Vital y Móvil 6 .

En ese sentido, esta exclusividad de la prestación obliga a que las personas con discapacidad que acceden a la misma, vivan en condiciones de pobreza, pudiendo percibir únicamente ese monto de dinero, sin tener la posibilidad de acceder a otra prestación contributiva, (como una pensión por cónyuge jubilado fallecido), ni que algún familiar o entidad los apoye, o la posibilidad de trabajar, ya que, de ser así, la pensión resulta incompatible (RALS, CELS y REDI, 2003; AA.VV, 2012; OISS, 2014; Sorgi y Calderón, 2017).

Se considera que la incompatibilidad con el empleo se basa en el supuesto de que estas personas se encuentran imposibilitadas de realizar actividades laborales debido a sus particularidades orgánico-anatómicas, funcionales o cognitivas. O lo podría denominarse como una incapacidad natural para el trabajo. En esta lógica, el término discapacidad se interpreta como una situación de «enfermedad», como la consecuencia de una deficiencia personal que la sociedad debe asumir.

\section{PERÍODO 2003-2015. ADECUACIÓN FÁCTICA DE LAS CONDICIONES DE ACCESO. EXPANSIÓN DE LA COBERTURA Y RECONOCIMIENTO DEL DERECHO A LA SEGURIDAD SOCIAL}

Como se señaló en el apartado precedente, el Decreto 432 que en 1997 reglamenta el conjunto de PNCA, presenta un carácter significativamente restrictivo en sus condiciones de acceso, situación que en las pensiones por invalidez se tradujo en una baja cobertura ${ }^{7}$. Ya se indicó, además, que resultaban incompatibles con otras prestaciones y, principalmente, con la inserción en el mercado laboral de sus destinatarios. A su vez, el acceso restrictivo promovía la dependencia de estas personas respecto a sus grupos familiares.

Sin embargo, las restricciones no se limitaban únicamente a las condiciones para acceder a las pensiones por invalidez, sino que la focalización fue acompañada de limitaciones presupuestarias extremas. Durante el período 1997-2003 la asignación de nuevas PNCA se basaba en un criterio de cupos, es decir, quedaba supeditado a una baja equivalente en los beneficios ya otorgados de manera de no afectar el crédito presupuestario anual asignado. Sólo se podían realizar altas cuando hubiera bajas, esto significó, en la práctica, que sólo se admitía un nuevo ingreso al sistema cuando alguna persona cubierta fallecía (Comité de Evaluación del Seguimiento de la Convención Interamericana para la Eliminación de Todas las Formas de Discriminación Contra las Personas con Discapacidad, 2003; Acuña y Bulit Goñi, 2010; Rofman, Apella y Vezza, 2013; Lombardía y Rodríguez, 2015; Danani, 2016; Britos y Caro, 2018).

\footnotetext{
6 A diciembre del 2019 el Salario Mínimo Vital y Móvil vigente era de \$ 16.875, con lo cual el valor de la pensión no contributiva por invalidez representaba apenas el $47 \%$ de esa remuneración. [Ver: https://www.argentina.gob.ar/noticias/nuevo-aumento-del-salario-minimo-vital-y-movil-y-de-la-prestacion-por-desempleo].

7 Entre 1999 y 2003, se observa un relativo estancamiento en la cobertura de las pensiones no contributivas, ya que el número de beneficios pasó de 346 mil a 345 mil. Particularmente, la cantidad de beneficiarios de las pensiones no contributivas por vejez e invalidez estuvo prácticamente congelada (BERTRANOU et al., 2011: 111).
} 


\subsection{Ampliación del derecho a la seguridad social en un marco de escasa institucionalidad}

La situación descripta en el apartado anterior se modificó sustancialmente a partir del año 2003 hasta el año 2015, período de los gobiernos de Néstor Kirchner y Cristina Fernández de Kirchner, que supuso una importante expansión de la cobertura ${ }^{8}$, e inauguró una nueva perspectiva en materia de protección social ${ }^{9}$.

En este período se observan cambios significativos en los criterios de implementación de las PNCA, entre los que se destaca la ampliación presupuestaria. Así el criterio de asignación de las PNCA deja de estar asociado a un cupo pre-existente, y se justifica por la sola presencia de alguno de los tres motivos previstos en las normativas. Además, se supera la restricción presupuestaria, dejando de lado el criterio de «alta por baja». Este criterio, vigente desde el año 1998, período fiscal siguiente a la sanción del Decreto 432, es modificado en el año 2003 mediante el Decreto $N^{\circ} 583$ que cambia el Artículo 40 de la Ley $N^{\circ} 25.725$ del Presupuesto de la Administración Nacional para el ejercicio 2003, eliminando las restricciones presupuestarias para su otorgamiento, lo que contribuyó a la expansión de la cobertura (Bertranou et al., 2011; Rofman, Apella y Vezza, 2013; Danani, 2016; Mallardi y Fernández, 2019). En ese sentido, en este período se observa un cambio explícito en la asignación de las prestaciones, pasando de un criterio sólo ligado al impacto económico-financiero de la prestación a otro basado en la perspectiva de derechos humanos.

En esa línea, además de la ampliación del presupuesto, se implementaron algunos cambios notables en las condiciones de acceso a las pensiones por invalidez, que también favorecieron al incremento de la cobertura. Por un lado, se asigna mayor peso relativo a los criterios socioeconómicos y ambientales en relación a los orgánico-anatómicos. De esta manera, la situación de vulnerabilidad social de los/as postulantes relativiza el porcentaje médico-legal del $76 \%$ de incapacidad laboral, lo cual supuso un avance en la desmedicalización de los sujetos destinatarios de estas prestaciones, convirtiendo en más accesible su asignación. Por otro lado, comienza a otorgarse prestaciones a menores de 18 años, para posibilitar procesos de rehabilitación y garantizar el derecho a la protección social en niños y niñas (Comisión de Discapacidad CPSSPC, 2018: 3). Simultáneamente, fueron revisados los parámetros de ingresos familiares, la condición de tenencia de la vivienda y el patrimonio en general, y los umbrales que se establecerían para reconocer la situación como de «máxima vulnerabilidad». Al mismo tiempo:

«se elevaron significativamente los ingresos tomados como topes para el otorgamiento de los beneficios; se aceptaron condiciones patrimoniales bajas, pero no necesariamente de indigencia (por ejemplo vivienda propia y automóvil con diez años de antigüedad)» (Danani, 2016: 14).

Además, se amplía la cobertura incorporando nuevas patologías que no generan necesariamente una incapacidad laborativa (Danani, 2016). En estos casos, además de contemplarse las dificultades para el acceso al mercado de trabajo formal, también se consideran las altas erogaciones en tratamientos, fármacos y alimentos específicos. En ese sentido, se asignan prestaciones a personas con hemofilia infectadas con los virus de HIV, hepatitis B y hepatitis C; (leyes 25.869/2004 y 26.850/2013), así también a personas con diabetes (Ley $N^{\circ} 26.914 / 2013$ ), con celiaquía (Ley $N^{\circ} 26.588 / 2009$ ) y a personas trasplantadas (Ley $N^{\circ} 26.928 / 2013$ ).

Ahora bien, resulta sorprendente advertir que estos cambios no fueron producto de una modificación de lo establecido en el Decreto 432 o de su derogación, es decir, «no se debieron a un cambio en las reglas y requerimientos de calificación de beneficiarios» (Rofman, Apella y Vezza, 2013: 78), o a una reforma formal (Danani, 2016) sino que fueron el resultado de una adecuación fáctica de las condiciones de acceso a los mínimos exigibles en materia del derecho a la seguridad social de las personas con discapacidad, establecidos por el derecho internacional de derechos humanos a través de Declaraciones, Convenciones y Pactos.

En ese sentido, Martínez (2018) plantea que Varina Suleiman, abogada de la Red por los Derechos de las Personas con Discapacidad (REDI), expresó que en la gestión gubernamental de este período "administrativamente se flexibilizaron los requisitos para el otorgamiento de estos beneficios». A pesar de que el Decreto 432/97 no se derogó, su no aplicación «permitió que la Argentina se alineara con el compromiso de

8 El proceso de expansión de la cobertura puede ser graficado a través de datos censales. La Encuesta Nacional de Personas con Discapacidad (ENDI), complementaria del Censo 2001 desarrollada entre los años 2002 y 2003 difundió que sólo el $7,2 \%$ del total de la población con discapacidad percibía una pensión a causa de su discapacidad (INDEC, 2006: 55). Siete años más tarde, el Censo 2010 informó que el $23,7 \%$ de esta población era destinataria de una pensión no contributiva por invalidez (INDEC, 2014: 64-67). Comparando estos datos, se puede constatar el incremento significativo en la cantidad de personas que perciben esta prestación. En el período intercensal 2003-2010 el incremento es de $242 \%$.

9 Para una caracterización de los cambios implementados en ese período en materia de PNCA, remitirse a LOMBARDÍA y RODRÍGUEZ (2015), DANANI (2016), BRITOS y CARO (2018) y MALLARDI y FERNÁNDEZ (2019). 
protección de las personas con discapacidades, de acuerdo con la Convención sobre los Derechos de las Personas con Discapacidad de la ONU que el país firmó en 2008» (5 de octubre de 2018).

Una adecuación fáctica comprende modificaciones aplicadas de manera facultativa por los equipos técnicos o de gestión responsables de la implementación de un programa o política social, sin que exista una normativa que las instituya. Se trata de innovaciones en los procesos de gestión de una política pública exentos de legitimidad normativa. Remite a lo que Danani (2016: 13) denomina «redefinición de las condiciones empíricas para el cumplimiento de los requisitos que caracterizan a cada beneficio». En ese sentido, si bien contribuye a flexibilizar el acceso a determinadas prestaciones, se caracteriza por la escasa institucionalización de sus cambios.

Además del incremento en el presupuesto y de la adecuación fáctica realizada, desde el año 2004 se ejecutaron algunas acciones complementarias que igualmente contribuyeron a la extensión de la cobertura de estas prestaciones. Se realizaron campañas de difusión acerca de la posibilidad de acceder a las pensiones; se abrieron nuevos Centros de Atención Personalizada, en los que se daba inicio y seguimiento a los trámites de altas de beneficios; se realizaron operativos de campo en zonas rurales, localidades aisladas o de difícil acceso y en zonas de alta vulnerabilidad; se avanzó en la modernización de los sistemas informáticos, lo que permitió disminuir el tiempo de evaluación de los expedientes y reducir el período que media entre el inicio del trámite, la aprobación del beneficio y su efectivo cobro; se suscribieron convenios de colaboración con universidades y municipios; se organizaron capacitaciones en provincias, municipios y organizaciones de la sociedad civil dirigidas al personal médico respecto a la perspectiva de derechos humanos, y se desarrollaron tareas conjuntas con la Administración Nacional de la Seguridad Social (ANSeS) para otorgar el alta del CUIL a los postulantes, entre otras acciones (Acuña y Bulit Goñi, 2010; Bertranou et al., 2011; Arcidiácono, 2019).

Como se puede advertir, la adecuación fáctica y las acciones complementarias desarrolladas en este período, implicaron una mejora progresiva en el reconocimiento del derecho a la seguridad social de las personas con discapacidad, compromiso asumido por el Estado argentino al ratificar tratados internacionales de derechos humanos como la Convención sobre los Derechos de las Personas con Discapacidad. Esta mejora se expresó en la universalización del acceso a las pensiones por invalidez a partir de la ya mencionada expansión de su cobertura.

Tabla 1. Pensiones no contributivas por invalidez. Período 2003-2015

\begin{tabular}{cc}
\hline Año & $\begin{array}{c}\text { Pensiones no contributivas } \\
\text { por invalidez }\end{array}$ \\
\hline 2003 & 80.593 \\
\hline 2004 & 89.407 \\
\hline 2005 & 123.458 \\
\hline 2006 & 154.694 \\
\hline 2007 & 201.477 \\
\hline 2008 & 264.311 \\
\hline 2009 & 372.715 \\
\hline 2010 & 504.946 \\
\hline 2011 & 654.735 \\
\hline 2012 & 795.775 \\
\hline 2013 & 917.394 \\
\hline 2014 & 1.018 .165 \\
\hline 2015 & 1.058 .835 \\
\hline
\end{tabular}

Fuente: Elaboración propia en base a Ministerio de Salud y Desarrollo Social (2018: 85).

Como se observa en la Tabla 1, al inicio de este período había 80.593 perceptores de pensiones por invalidez, cantidad que se eleva a 1.058.835 en el 2015, año de finalización de la gestión de Cristina Fer- 
GAPP. Nueva Época - N. ${ }^{\circ}$ 24, noviembre 2020 - ISSN: 1989-8991 - DOI: https://doi.org/10.24965/gapp.i24.10732 - [Págs. 86-105]

Transformaciones normativas recientes en el derecho a la seguridad social de las personas con discapacidad en Argentina

Mauricio Mareño Sempertegui / Nora Britos

nández de Kirchner. El incremento absoluto en 12 años fue de 978.242 perceptores, lo que supone un incremento porcentual de $1.214 \%$ entre 2003 y 2015.

Por otro lado, tomando los datos presentados por CEPA (2017) y Reati (2019), se advierte que en este período se habrían asignado un total de 1.284.374 nuevas pensiones por invalidez. Si consideramos los datos del Censo Nacional de Población, Hogares y Viviendas del año 2010, podemos estimar que las nuevas altas de este período cubrían al $25 \%$ de la población con discapacidad ${ }^{10}$.

Tabla 2. Pensiones por invalidez. Nuevas altas otorgadas. Período 2003-2015

\begin{tabular}{|c|c|c|c|c|c|c|c|c|c|c|c|c|c|}
\hline 2003 & 2004 & 2005 & 2006 & 2007 & 2008 & 2009 & 2010 & 2011 & 2012 & 2013 & 2014 & 2015 & Total \\
\hline 2.71 & 4.980 & 1.092 & 47.023 & .271 & 77.478 & 170.107 & 145.745 & 158.813 & 172.509 & 132.193 & 126.524 & 124.928 & 1.284 .374 \\
\hline
\end{tabular}

Fuente: Elaboración propia en base a CEPA (2017: 1) y Reati (2019: 2).

Resulta evidente que los cambios efectuados en este período, respecto a la implementación de las PNCA y en las pensiones por invalidez en particular, impactaron significativamente en la extensión de su cobertura. El incremento porcentual entre las nuevas pensiones por invalidez asignadas en el año 2003 y en el año 2015 es de un $4.508 \%$, es decir, entre estos años se incrementó 45 veces la cantidad de nuevas altas por año.

Gráfico 1. Pensiones por invalidez. Nuevas altas otorgadas por año. Período 2003-2015

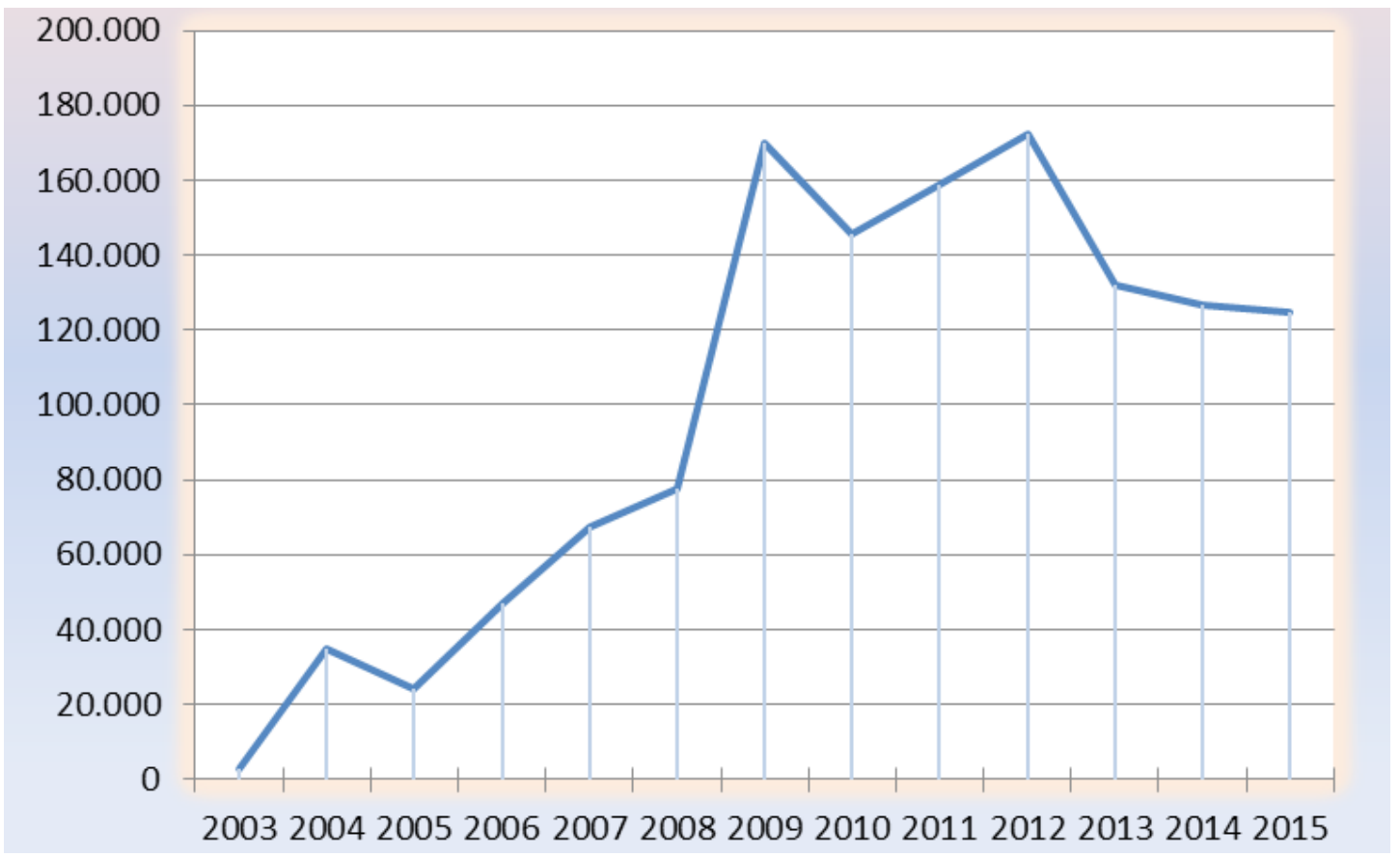

Fuente: Elaboración propia en base a CEPA (2017: 1) y Reati (2019: 2).

Como se puede observar en el Gráfico 1, resulta concluyente el aumento de las nuevas altas entre el año 2003 y el 2004 (momento en el que se comienzan a implementar gran parte de los cambios antes seña-

10 El censo del año 2010, denominado "Censo del Bicentenario", incluyó temáticas tales como el recuento, identificación y localización de pueblos originarios, población afrodescendiente y personas con discapacidad. Estas últimas son definidas como «personas con dificultad o limitación permanente» y su relevamiento se incluyó en el denominado "cuestionario ampliado», aplicado a una muestra de la población de las localidades de 50.000 habitantes y más, y a toda la población de las localidades de menos de 50.000 habitantes. Este censo computó un total de 5.114.190 personas con dificultad o limitación permanente en todo el país, lo que representa el 12,9\% del total de la población (INDEC, 2012). 
lados), entre esos años la cantidad de nuevas altas se multiplica por doce veces. El año en el que se registra la menor cantidad de altas es el 2005, con 24.092 nuevas incorporaciones, y en el año 2012 se observa el valor más alto: 172.509 nuevas prestaciones. Posteriormente se percibe una baja sostenida hasta la finalización de este período en el año 2015. En ese sentido, (Reati, 2019: 2) señala que «a partir del año 2012 disminuye la cantidad de nuevas solicitudes debido a que se fue logrando cubrir la demanda "vegetativa"». El promedio de nuevas altas por año en todo el período es de 98.798 .

En este contexto, algunos grupos y personas históricamente excluidas de los sistemas de protección social, o que simplemente no encuadraban en el perfil de sujeto destinatario de una pensión no contributiva, debido a las condiciones restrictivas de su normativa reglamentaria ${ }^{11}$, fueron reconocidas como sujetos con derecho a la seguridad social ${ }^{12}$.

Recapitulando, los gobiernos de Néstor Kirchner y Cristina Fernández de Kirchner no modificaron formalmente las condiciones de acceso a las pensiones por invalidez, ni derogaron la normativa que las regula (Decreto 432/1997), dejando así endebles y con escasa institucionalidad todos los cambios progresivos que supuso la adecuación fáctica que se desarrolló en este período. Esto sucedió a pesar de las indicaciones del derecho internacional de derechos humanos, como la Observación General 3 del Comité DESC (1990) respecto a "La índole de las obligaciones de los Estados Partes":

«El Comité reconoce que en numerosos casos las medidas legislativas son muy deseables y en algunos pueden ser incluso indispensables. Por ejemplo, puede resultar difícil luchar con éxito contra la discriminación si se carece de una base legislativa sólida para las medidas necesarias» (Comité DESC, Observación General 3, párrafo 3).

Y pese a las recomendaciones de organizaciones de la sociedad civil, que desde comienzos del siglo XXI plantearon en varios informes y de manera sistemática, que las condiciones de acceso a estas prestaciones debían reformularse, debido a su naturaleza restrictiva. En ese sentido, el Primer Informe Alternativo para el Comité sobre los derechos de las personas con discapacidad (AA.VV, 2012) recomendaba sobre el derecho a la protección social:

«Adoptar todas las medidas legislativas, administrativas o de otra índole que sean pertinentes para reformular los requisitos exigidos por el decreto reglamentario 432/1997 para acceder a la pensión por motivos de discapacidad a efectos de hacer efectivo los derechos reconocidos en el Artículo 28 de la CDPD» (pág. 76).

En este marco, la no derogación de una normativa contraria a los derechos humanos reconocidos en el ámbito nacional, fue quizás la mayor omisión de este período, omisión que supuso una violación del derecho a la seguridad social de las personas con discapacidad, ya que según la Observación General N 19 del Comité DESC (2008):

«Las violaciones por actos de omisión pueden ocurrir cuando el Estado Parte no adopta medidas suficientes y apropiadas para garantizar el ejercicio del derecho a la seguridad social. En el contexto de la seguridad social, algunos ejemplos de esas violaciones son la no aplicación de la legislación pertinente o de las políticas destinadas a garantizar el ejercicio efectivo del derecho a la seguridad social; el no reformar o derogar la legislación manifiestamente incompatible con el derecho a la seguridad social; el no cumplir sus obligaciones básicas» (Comité DESC, Observación General 19, párrafo 65).

\section{PERÍODO 2016-2019. ÉPOCA DE TRANSFORMACIONES REGRESIVAS EN LAS NORMAS JURÍDICAS Y EN LOS RESULTADOS DE LA POLÍTICA DE PENSIONES NO CONTRIBUTIVAS}

Con la asunción del gobierno de Mauricio Macri a finales del año 2015, se inicia el proceso de reorganización de la protección social en Argentina, en un contexto de reconstrucción neoliberal caracterizado por

11 Se hace alusión a personas con discapacidad apartadas del mercado laboral formal con incapacidades laborativas menores al $76 \%$, con una situación patrimonial devaluada pero no de indigencia o desafiliación, menores de 18 años, así como personas con diagnósticos que no suponen necesariamente una incapacidad para trabajar: hemofílicas infectadas con los virus de HIV, hepatitis B y hepatitis $\mathrm{C}$; con diabetes; con celiaquía y trasplantadas.

12 Como se indicará más adelante, esto no sucedió con las personas extranjeras con residencia continua en el país menor a 20 años. 
el ajuste y retracción del gasto público social. En ese marco, «los fundamentos de la protección social como actividad estatal fueron puestos en cuestión y rediseñados» (Hopp y Lijterman, 2019: 68).

En este contexto, el sistema de previsión social y el subconjunto de PNCA son objeto de retrocesos significativos ${ }^{13}$. Así, la política de pensiones por invalidez es objeto de un conjunto de reformas regresivas tanto en sus normativas como en sus resultados. Respecto a la regresividad normativa (Courtis, 2006) en este período se aprueban los Decretos de Necesidad y Urgencia (DNU) 698/2017 y 95/2018 que modifican significativamente la institucionalidad político-administrativa de las pensiones por invalidez y del resto de las políticas estatales orientadas a la población con discapacidad. A su vez, también se aprueban las Resoluciones 268/2018, 39/2019 y 44/2019 de la Agencia Nacional de Discapacidad (ANDI), que basadas en la sospecha de la existencia de receptores ilegítimos de pensiones (debido a la significativa expansión de la cobertura en el período anterior), se orientan a transparentar la asignación de nuevas prestaciones y a evitar posibles fraudes.

Por otra parte, la regresividad en los resultados de la política (Courtis, 2006) de pensiones por invalidez se expresa en la implementación taxativa del Decreto 432/ 1997, que al prescindir de la adecuación fáctica del período anterior, derivó en una "cacería de incompatibilidades» y la consecuente suspensión y baja masiva de prestaciones.

De esta manera, tanto a partir de la generación de nuevas normativas como a través de los resultados de la implementación de la política de pensiones por invalidez, el gobierno de este período coartó el derecho a la seguridad social de las personas con discapacidad.

\subsection{Regresividad normativo-jurídica. Centralización y combate contra el (presunto) fraude}

Los DNU 698/2017 y 95/2018 conllevaron un cambio sustancial en el aparato institucional de gestión de las pensiones por invalidez. Según lo estipula su texto responden a la necesidad de iniciar un proceso de centralización y concentración de todas las políticas y cuestiones vinculadas a las personas con discapacidad, en un único organismo especializado.

En ese sentido, en septiembre de 2017, el DNU 698, establece la creación de la ANDI, organismo descentralizado dependiente de la Secretaría General de la Presidencia, con autarquía económico-financiera y personería jurídica propia. Cuya finalidad es «el diseño, coordinación y ejecución general de las políticas públicas en materia de discapacidad, la elaboración y ejecución de acciones tendientes a promover el pleno ejercicio de los derechos de las personas en situación de discapacidad y la conducción del proceso de otorgamiento de las pensiones por invalidez» (DNU N 698, 2017: art. 1).

Cabe destacar que este Decreto establece a su vez la disolución de la Comisión Nacional Asesora para la Integración de las Personas con Discapacidad (CONADIS) ${ }^{14}$ y la Comisión Nacional de Pensiones Asistenciales (CNPA) ${ }^{15}$, así como la transferencia de sus funciones, presupuesto, personal y bienes a la órbita de la mencionada Agencia (DNU N 698, 2017: art. 8).

La disolución de la CONADIS generó una gran incertidumbre respecto al destino de los Comités que la conformaban, y sobre todo del Consejo Federal de Discapacidad que, en alguna medida, garantizaba la participación de las entidades gubernamentales y organizaciones no gubernamentales en materia de discapacidad de todas las provincias, y en ese sentido, el diálogo y la concertación multiactoral e intersectorial en torno a las políticas a implementar.

Por su parte, al disolverse la CNPA se suscitan un sinfín de interrogantes en torno a la continuidad de los más de setenta Centros de Atención Local $(\mathrm{CAL})^{16}$ que conformaban su estructura organizativa y que se

13 Para un descripción pormenorizada de las transformaciones regresivas en la política de previsión social, que se inician en el año 2016, remitirse a DVOSKIN (2016), CORSIGLIA (2018), BERTRANOU et al. (2019), BRITOS y CARO (2019) y HOPP y LIJTERMAN (2019). Para un examen análogo respecto a las PNCA a FINDLING, VENTURIELLO y CIRINO (2018) y MALLARDI y FERNÁNDEZ (2019).

14 La Comisión Nacional Asesora para la Integración de las Personas con Discapacidad (CONADIS) se crea en el año 1987, a través del Decreto $N^{\circ}$ 1.101. Dependía del Consejo Nacional de Coordinación de Políticas Sociales de la Presidencia de la Nación y constituyó el ente interorgánico de coordinación y asesoramiento en materia de políticas sobre discapacidad. (MORO y POTENZA DAL MASETTO, 2010).

15 La Comisión Nacional de Pensiones Asistenciales (CNPA), fue creada en el año 1996, por Decreto N 1455, entre sus funciones se incluía la tramitación, otorgamiento, liquidación y pago de PNCA y las emergentes de leyes especiales, como así también la cobertura asistencial médica a la población beneficiaria dependiente de su jurisdicción (MALLARDI y FERNÁNDEZ, 2019).

16 Los Centros de Atención Local (CAL) se crearon en el año 2003 y eran oficinas ubicadas en todas las provincias del país, abocadas a la gestión local y realización de todo tipo de trámites relacionados a las pensiones por invalidez, y otras prestaciones orientadas 
distribuían en el conurbano bonaerense y en el interior del país. El cierre de los CAL fue paulatino pero sin pausa, hasta su virtual desaparición en el año 2019, momento en el que la ANDI establece que la gestión de las pensiones por invalidez migrará del Ministerio de Desarrollo Social a la ANSeS ${ }^{17}$. Todos estos cambios tuvieron como argumento oficial «la necesidad de transparentar la asignación de pensiones por invalidez», no obstante, en los hechos supusieron la pérdida de espacios institucionales de atención profesional y personalizada, que desde una gestión territorial, intersectorial e intergubernamental, contribuían al acceso a la información y a las prestaciones estatales en este sector de la población.

Por otro lado, a través del DNU 95 del 2018, también se disuelve el Servicio Nacional de Rehabilitación $(\mathrm{SNR})^{18} \mathrm{y}$, al igual que lo sucedido con la CONADIS y la CNPA, la ANDI absorbe sus funciones, presupuesto, personal y bienes. De esta manera, la ANDI amplía sus funciones incorporando «la formulación y ejecución de políticas nacionales de rehabilitación para personas con discapacidad», la definición de «los modelos prestacionales más adecuados para la cobertura médica establecida para los beneficiarios de las Pensiones No Contributivas», y «todo lo ateniente a la certificación de la discapacidad» (DNU N 95, 2018: art. 7).

La falta de discusión en fueros públicos para la creación de la ANDI y la intempestiva decisión sobre la disolución de la CONADIS, la CNPA y el SNR, no fue puesta a consideración ni consultada con los miembros del Consejo Federal de Discapacidad, ni con los organismos y entidades que abogan por los derechos de este sector poblacional, con lo cual «se incumple uno de los preceptos y obligaciones generales de la Convención referido a la participación organizada de las personas con discapacidad en los procesos de adopción de decisiones sobre políticas y programas, incluidos los que les afectan directamente» (ONU, 2006: 3; Findling, Venturiello y Cirino, 2018: 79).

En este marco, podría plantearse que las modificaciones efectuadas en el aparato institucional de la política de pensiones por invalidez durante este período, presentan un carácter anticonvencional.

Continuando con la generación de normativa regresiva, entre el año 2018 y 2019 el Estado Nacional aprueba y pone en vigencia una serie de instrumentos legales y procedimentales orientados a la identificación de incompatibilidades con el Decreto 432 respecto a la asignación de pensiones por invalidez. Como así también, dirigidos a transparentar la asignación de nuevas prestaciones y a controlar y evitar posibles fraudes (Resoluciones ANDI 268/2018, 39/2019 y 44/2019). La sospecha sobre la presencia de receptores ilegítimos de la asistencia del Estado será el fundamento para desarrollar una maquinaria normativo-administrativa destinada a verificar la «legítima dependencia» (Grassi, 2018) de los destinarios de estas prestaciones.

En tal sentido, en el mes de septiembre de 2018, la ANDI a través de su Resolución 268, aprueba un nuevo circuito administrativo de notificación de incompatibilidades, suspensión y caducidad de pensiones por invalidez. Esta Resolución intenta inaugurar un intrincado proceso de actualización y verificación de información de los titulares de pensiones por invalidez en los que se detectaron incompatibilidades, tendiente a avanzar hacia su baja si se comprueban irregularidades. Una vez que este sistema de control identifica titulares que presentan incompatibilidades y las notifica, establece un plazo de diez días hábiles a contarse desde el día siguiente de la notificación, para que estos puedan «ejercer su legítimo derecho de defensa y ofrecer la prueba de la que intentaren valerse, como así también tomar vista de las actuaciones» (Res. $\left.N^{\circ} 268,2018: 1\right)$. En ese plazo, los/as titulares notificados deberán:

«comunicarse telefónicamente al número 130 a efectos de combinar turno en la dependencia de ANSeS más cercana a su domicilio, actualizar sus datos personales y presentar su descargo y/o renuncia al beneficio. El personal de ANSeS brindará asesoramiento respecto de la documentación a presentar para dar respuesta a las incompatibilidades observadas y le otorgará un turno a fin de presentar la misma en la oficina de ANSeS más próxima a su domicilio» (Res. $\mathrm{N}^{\circ} 268,2018: 8$ ).

Según esta Resolución, los titulares que presenten el descargo continuarán una serie de procedimientos en los que ANSeS analizará la documentación presentada, cruzará datos y asignará un nuevo

\footnotetext{
a la población definida como discapacitada. Representaban a la CNPA en el ámbito de sus jurisdicciones y constituían el primer punto de contacto para iniciar la gestión de estas prestaciones.

17 Proceso que se había iniciado en el 2017 con las pensiones no contributivas para madres de siete hijos/as o más.

18 El Servicio Nacional de Rehabilitación (SNR) fue creado en 1956, en el contexto de la epidemia de polio, y fue el organismo más antiguo en el país en materia de políticas de discapacidad. Dentro del sector salud, el SNR se posicionaba como el organismo rector en lo referente a la normativización y ejecución de las políticas vinculadas a la rehabilitación e integración de este colectivo (MORO y POTENZA DAL MASETTO, 2010).
} 
turno si se registra un faltante de documentación. Si los titulares brindan una justificación adecuada a la incompatibilidad observada recibirán un mensaje informando que la documentación presentada «obtuvo un análisis favorable». En caso contrario, se procederá a la suspensión y posterior caducidad de la prestación.

De esta manera, las personas con discapacidad receptoras de una pensión por invalidez se convierten en sujetos sospechados y son obligados a comprobar su condición de legítimos merecedores de un derecho adquirido. Como se observa, se trata de una sospecha que presenta varias aristas, a saber, la sospecha sobre las condiciones de admisibilidad a las prestaciones aplicadas en el período anterior, sobre el carácter lícito de sus receptores, y por ende, sobre la legitimidad de su derecho a la seguridad social.

Por otro lado, la operatoria establecida para que los beneficiarios notificados presenten su descargo, es decir, la obligación de solicitar un turno telefónicamente en el plazo de diez días y, en ese lapso, reunir sus historias clínicas, certificado médico oficial, y otros documentos que acrediten su condición, bajo de pena de caducidad de la prestación, supone una exigencia injustificada y arbitraria. Como plantea el Comité DESC (2018) «el derecho a la seguridad social incluye el derecho a no ser sometido a restricciones arbitrarias o poco razonables de la cobertura social existente» (Comité DESC, Observación General 19, párrafo 9). En ese sentido, se considera que esta Resolución intentó ser el instrumento normativo necesario para justificar la masiva baja y suspensión de prestaciones acontecida entre los años 2016 y 2017, que se analizará más adelante.

Bajo el mismo imperativo de controlar y evitar nuevos fraudes, en enero del 2019 y a través de la Resolución 39, la ANDI establece la creación del Circuito de Confección del Certificado Médico Oficial (CMO), como así también del nuevo Formulario Certificado Médico Oficial (FOCME), documentos imprescindibles para la solicitud de estas prestaciones ya que autentifican la invalidez laboral. Esta normativa establece que su gestión será a través de la Plataforma de Trámites a Distancia (TAD), lo que supone la digitalización de la gestión de nuevas solicitudes y la creación de un nuevo Certificado Médico en soporte digital.

En esa línea, en febrero de ese año, la Resolución 44 aprueba el Circuito Administrativo de Renovación de Certificados Médicos Oficiales de Pensiones no Contributivas de Invalidez. Esta nueva normativa obliga a los/as titulares de pensiones por invalidez a revalidar su condición on line en un plazo de sesenta (60) días, es decir, a que actualicen su certificado médico y que registren su situación a través de internet. Los titulares ya no podrán presentar su Certificado Médico Obligatorio firmado por cualquier profesional, ahora deberán presentarse a un hospital público y sus datos serán cargados «a distancia», a través del mecanismo creado para informatizar los procedimientos en el Estado a través del Decreto $N^{\circ}$ 1063/2016.

Como se puede observar, estas nuevas pautas para la confección y renovación de certificados médicos, parecen desconocer la validez del actual Certificado Único de Discapacidad como instrumento público, imponiendo un nuevo trámite (ahora en formato digital) a aquellas personas que ya certificaron oficialmente su condición.

Además, las mencionadas resoluciones presentan una excesiva confianza en los beneficios de la tecnología para la resolución de procedimientos administrativos. Parecen asumir una relación directa, incluso causal, entre la gestión virtual de estos procedimientos y su consecución exitosa:

«A los efectos de brindar la más efectiva y eficiente obtención de la información de los solicitantes de los Certificados Médicos Oficiales de Pensiones no Contributivas por Invalidez, se considera oportuno establecer que la confección y suscripción de éstos se realice por intermedio de la Plataforma Trámites a Distancia (TAD), lo cual permitirá una sustancial mejora en la medición en la eficacia y la eficiencia en el cumplimiento de los objetivos propuestos por la AGENCIA NACIONAL DE DISCAPACIDAD en materia de cumplimiento de los requisitos previstos en el Decreto № 432/97». (Res. N³9/2019, pág. 2)

Una confianza en la tecnología que omite significativamente la cuestión de la accesibilidad en la elaboración y gestión del $\mathrm{CMO}$ digital, requisito fundamental para este pueda emitirse. Hacemos referencia a algunas condiciones básicas de accesibilidad que debieran contemplarse, a saber, existencia de computadoras y conexión en línea en todos los hospitales públicos a los que las personas notificadas deban asistir a realizar el trámite, instalación de dispositivos de accesibilidad en las computadoras (por ejemplo, lectores de pantalla y magnificadores de caracteres), garantía de accesibilidad web en las plataformas digitales utilizadas, procedimientos alternativos para aquellas personas que no puedan acceder a hospitales públicos ya sea por ausencia de accesibilidad urbana, edilicia y comunicacional en estos recintos, por ubicación geográfica o por fragilidad en las condiciones de salud. 
Por todo lo dicho, estas normativas parecen desconocer las posibles dificultades que pueden presentarse en las instituciones de salud de las provincias y los municipios, que podrían tener como consecuencia la baja de algunas prestaciones, ya que pasado el plazo de 60 días para realizar las diligencias establecidas, la baja de la pensión es automática.

En tal sentido, las Resoluciones 39 y 44 inauguran un proceso de burocratización digital en la gestión de las pensiones por invalidez, que en los hechos opera como un obstáculo al ejercicio del derecho a la seguridad social de las personas con discapacidad. Una barrera administrativa en los procedimientos y tiempos de gestión de las prestaciones que supone un retroceso en materia de derechos sociales.

\subsection{Regresividad de resultados. Interpretación taxativa de la normativa y compulsiva baja-suspensión de pensiones por invalidez}

Como se señaló en el apartado anterior, en este período se generó una serie de normativas que, cimentadas en la sospecha de la asignación indiscriminada, discrecional y clientelar de prestaciones entre los años 2003 y 2015, proponen transparentar su gestión en un marco de «saneamiento» de la administración pública.

Bajo esa misma finalidad, y de manera complementaria, se comenzaron a aplicar taxativamente las condiciones para evaluar las solicitudes de pensiones por invalidez, asignar nuevas y valorar las entregadas en el período anterior, establecidas en el Decreto Reglamentario 432/97. Esta interpretación coercitiva de la norma ${ }^{19}$ basada en la «ideología del mérito individual», que establece quienes son legítimos merecedores de la asistencia del Estado y quienes no, generó la consecuencia quizás más tematizada y politizada de la regresividad propia de este período: la inesperada y masiva baja y suspensión de PNCA y específicamente de pensiones por invalidez, acaecidas principalmente durante los años 2016 y 2017. De esta manera, la cuestión de la protección social de esta población, ingresa notoriamente en la agenda de los medios de comunicación y de la opinión pública, como así también, pero en menor medida, en los espacios académicos vinculados con las políticas sociales, el derecho y los derechos humanos.

En ese marco, desde septiembre del 2016 se inicia un análisis y valoración de las pensiones por invalidez asignadas en el período anterior, con el objetivo de identificar supuestas incompatibilidades. Estas giraban en torno a: a) Patrimonio: ser titular de un automóvil; b) Cónyuge con beneficio: el/la cónyuge ha recibido algún beneficio previsional; c) Ingresos propios: figurar en el sistema de aportes como receptor de ingresos por empleo; d) No acreditar incapacidad reglamentaria en ANSeS: al generarse un cruce de datos con la Auditoria Médica de ANSeS, no alcanzar el porcentaje de discapacidad para el acceso al beneficio previsional (76\%) (CEPA, 2017: 2-3). Así, para ser compatible a las condiciones fijadas por el Decreto 432, se debía estar en una situación de indigencia, fuera del mercado laboral y poseer una incapacidad biológica para trabajar, medida con criterios absolutamente biomédicos. Estas cualidades conformarían nuevamente el «perfil» de legítimo destinatario de pensiones por invalidez, análogo al perfil establecido antes del período 2003-2015. Como se recordará, en ese período se aplicó una adecuación fáctica de las condiciones de acceso a las prestaciones respecto a los estándares internacionales de derechos humanos, lo cual significó una mejora progresiva en el ejercicio del derecho a la seguridad social en las personas con discapacidad, expresada en la ampliación de la cobertura de las pensiones. No obstante, al no derogar o modificar el Decreto Reglamentario de 1997, todos los cambios y mejoras introducidas con la adecuación fáctica carecieron de institucionalidad. En ese escenario, el gobierno de Mauricio Macri simplemente omitió esa adecuación y se remitió literalmente a lo establecido en el contenido de la normativa reglamentaria, como justificativo legal para la suspensión y baja de las prestaciones. De este modo, el derecho a la seguridad social de las personas con discapacidad se restringe apelando a una normativa contraria al derecho internacional de derechos humanos.

En este contexto, a mediados del 2017 se conoció que entre los meses de enero y junio de ese año se habían eliminado un total de 83.133 PNCA, de las cuales 71.706 correspondían a pensiones por invalidez, considerando bajas y suspensiones (CEPA, 2017). Cantidad que se elevaría a 93.179 a finales de ese año (Reati, 2019). Cabe destacar que esta eliminación fue de carácter compulsiva e inconsulta, los/as titulares se enteraron de la medida al advertir la suspensión del depósito de dinero en sus cuentas bancarias. Al respecto, en un comunicado a la opinión pública la REDI planteó que «la aplicación del decreto, no cumplió con los

\footnotetext{
19 Que como se vio en el apartado 1 de este trabajo, presenta un carácter restringido en sí misma.
} 
requisitos básicos del debido proceso, que deben reunir los actos administrativos: citación de las personas afectadas, derecho a producir prueba, escucha de la persona y notificación en forma escrita de la decisión tomada» (21 de junio de 2017). En ese sentido, durante el período 2016/2017 «se dieron de baja un total de 153.263 pensiones por invalidez» (Mallardi y Fernández, 2019: 20).

La suspensión y baja coercitiva de estas prestaciones generó múltiples reacciones de rechazo en la sociedad, ya que para sus titulares suponen un ingreso mínimo, la cobertura de necesidades educativas, de transporte, de tratamientos médicos, de asistencia en el cuidado y necesidades específicas que implican un gasto fijo mensual, por ende, «dejar de percibirlas significa una severa afectación a sus derechos, a sus condiciones de vida y sus posibilidades de subsistencia» (AA.VV, 2017: 28).

Por todo lo anteriormente expuesto, se puede plantear que tanto las Resoluciones 268/2018, 39/2019 y 44/2019 de la ANDI, así como la masiva baja y suspensión de prestaciones ocurrida entre los años 2016 y 2017, incumplen el estándar internacional de no regresividad en materia de derechos económicos, sociales y culturales. Como se señaló en las primeras páginas de este trabajo, el principio de no regresividad supone.

«la prohibición de adoptar políticas y medidas, y por ende, de sancionar normas jurídicas, que empeoren la situación de los derechos económicos, sociales y culturales de los que gozaba la población al momento de adoptado el tratado internacional respectivo, o bien en cada mejora "progresiva"» (Courtis, 2006: 10).

La obligación estatal de abstenerse de adoptar medidas deliberadamente regresivas deriva de la obligación de progresividad en la satisfacción de derechos económicos, sociales y culturales, establecido en el artículo 2.1 del PIDESC y adoptado por varios instrumentos del sistema internacional de derechos humanos entre ellos la Convención sobre los Derechos de las Personas con Discapacidad, que en su artículo 4 de "Obligaciones Generales" señala:

«Con respecto a los derechos económicos, sociales y culturales, los Estados Partes se comprometen a adoptar medidas hasta el máximo de sus recursos disponibles y, cuando sea necesario, en el marco de la cooperación internacional, para lograr, de manera progresiva, el pleno ejercicio de estos derechos, sin perjuicio de las obligaciones previstas en la presente Convención que sean aplicables de inmediato en virtud del derecho internacional» (ONU, 2006; artículo 4, párrafo 2).

\subsection{Reacción organizada a los retrocesos en el derecho a la seguridad social: la Red por los Derechos de las Personas con Discapacidad (REDI)}

Los significativos retrocesos en el ejercicio del derecho a la seguridad de las personas con discapacidad, que alcanzaron su punto crítico con la baja de las pensiones por invalidez, generaron variadas reacciones de repudio en algunos sectores de la sociedad. En este marco, la Red por los Derechos por las Personas con Discapacidad (REDI), presentó varios recursos de amparo colectivo en representación de los destinatarios de las prestaciones. En junio del 2017, REDI inició una acción de amparo colectivo, para solicitar que se restablezcan las pensiones por invalidez a todas las personas con discapacidad que siendo titulares de estas prestaciones, se vieron impedidas de cobrar sus haberes a partir de junio de 2017. Además, pide que se declare la inconstitucionalidad del Decreto 432/97 por ser contrario a la Convención Internacional sobre los Derechos de las Personas con Discapacidad, ya que esa normativa reglamentaria exige a las personas destinatarias un determinado porcentaje de incapacidad laboral, omitiendo «las barreras debidas a la actitud y al entorno que evitan su participación plena y efectiva en la sociedad, en igualdad de condiciones con las demás» (ONU, 2006: 2).

En septiembre del 2017, el Juzgado Federal de la Seguridad Social № 8, emite un primer fallo positivo a favor de REDI, y ordena al Ministerio de Desarrollo Social de la Nación a que restablezca, en forma inmediata, el pago de las pensiones por invalidez que fueron dadas de baja o suspendidas sin mediar resolución previa fundada en procedimientos que garanticen el debido proceso desde el mes de enero de 2017.

Ese mismo mes, el Estado Nacional apela la sentencia judicial que lo obligaba a restablecer las pensiones por invalidez. Apelación que constituye una demostración evidente del incumplimiento estatal a lo establecido por el derecho internacional de derechos humanos. Por ejemplo, los artículos 28 y 19 de la Convención Internacional sobre los Derechos de las Personas con Discapacidad, que reconocen el derecho a la 
protección social y a la vida autónoma. Posteriormente a inicios de noviembre de ese año, REDI amplía la medida cautelar intimando al Estado a restablecer el pago de pensiones por invalidez a todas las personas a las que se les haya dado de baja desde enero del año 2016. Esta solicitud es presentada ante el juzgado de la Seguridad Social. A los 10 días de ese mismo mes, la Cámara Nacional de la Seguridad Social, Sala II, emite un segundo fallo positivo para REDI, dictando una sentencia interlocutoria en el proceso colectivo contra el Estado Nacional por la arbitraria e ilegítima suspensión de pensiones por invalidez. La sentencia resuelve rechazar la apelación interpuesta por el Estado contra la medida cautelar que ordena restablecer las pensiones.

La complejidad de los hechos antes descriptos, convirtieron al segundo semestre del año 2017 en un período en el que el conflicto judicial entre los receptores de pensiones por invalidez -representados por REDI-y el Estado Nacional, alcanza su mayor intensidad y presencia mediática. Como consecuencia el Estado Nacional se ve forzado a restituir algunas de las prestaciones suspendidas o dadas de baja, mientras que para justificar la continuidad de las suspensiones de un importante número apela a la vigencia del Decreto 432. En tal sentido, «solo se restituyeron 37.156 prestaciones de un total de 153.263 que fueron dadas de baja entre los años 2016 y 2017» (Mallardi y Fernández, 2019: 20). Es decir, apenas el $24 \%$ del total.

En 2018, REDI presenta un nuevo recurso de amparo, solicitando la declaración de inconstitucionalidad de la Resolución 268/2018, y en el mes de febrero de 2019, a través de nota dirigida al director ejecutivo de la ANDI, con copia a la vicepresidenta de la Nación, exige la suspensión de los nuevos controles instituidos en las Resoluciones 39 y 44 del año 2019. En el mes de marzo del 2019, la Sala II de la Cámara Federal de la Seguridad Social, emite un nuevo fallo positivo a favor de REDI. Esta sentencia definitiva resuelve que el Estado deberá restablecer las pensiones suspendidas o dadas de baja desde 2016, con lo cual se amplía la obligación de restitución, ya que la sentencia definitiva de primera instancia, emitida dos años antes, ordenaba restablecer las pensiones suspendidas o dadas de baja desde el año 2017. Asimismo, la sentencia declara la inconstitucionalidad e inconvencionalidad de la Resolución 268/2018 con respecto a la carga que les impone a los titulares de las pensiones por invalidez «para que se comuniquen telefónicamente al número 130 a efectos de combinar turnos en la dependencia de ANSeS más cercana a su domicilio, actualizar sus datos personales y presentar su descargo con respecto a las incompatibilidades detectadas», bajo pena de caducidad del beneficio. Con lo cual queda suspendida la exigencia de solicitar turnos telefónicos ya que este procedimiento «no protege las garantías constitucionales y convencionales de defensa» (Cámara Federal de la Seguridad Social, Sentencia definitiva, marzo 2019: 11).

Esta sentencia también declara la inconstitucionalidad e inconvencionalidad del artículo $1^{\circ}$ incisos «f», "g» y artículo $5^{\circ}$, inciso «a», primer párrafo, como también del artículo $1^{\circ}$ inciso «b», segundo párrafo, del Decreto N ${ }^{\circ} 432 / 97$; ya que transgreden lo establecido por la Convención sobre los Derechos de las Personas con Discapacidad, respecto al derecho a la protección social de este colectivo. Es decir se establecen como inconstitucionales las condiciones restrictivas analizadas en el primer apartado de este trabajo.

Por otra parte, en cuanto al pedido de suspensión de las Resoluciones 39/2019 y 44/2019 formulado por REDI, en el mes de abril del 2019 la Sala 2 de la Cámara Federal de la Seguridad Social lo rechaza «hasta tanto la sentencia pase en autoridad de cosa juzgada, habida cuenta que hasta el día de la fecha no se alegó ni se acreditó ningún perjuicio con respecto a dicha norma» (Cámara Federal de la Seguridad Social, Resolución judicial, abril 2019: 4).

\section{ALGUNAS CONCLUSIONES}

A lo largo de este trabajo se analizaron las transformaciones en el derecho a la seguridad social de las personas con discapacidad en Argentina durante los años 2003 y 2019, delimitando la mirada en la política de pensiones no contributivas por invalidez. En ese sentido, se examinaron las medidas adoptadas por el Estado nacional a través del análisis de su marco normativo, con base en la obligación de progresividad y la prohibición de regresividad en materia de derechos humanos.

Se observó que en el período comprendido entre los años 2003 y 2015, se produjo una sustancial expansión de la cobertura de pensiones por invalidez que universalizó su acceso en la población con discapacidad. Se advirtió, además, que esta expansión estuvo desprovista de condiciones de institucionalidad ya que no fue el resultado de la modificación o derogación de la normativa anticonvencional que regula las condiciones de acceso a estas prestaciones (Decreto Reglamentario 432/1997), sino producto de una adecuación fáctica de esas condiciones de acceso a los estándares internacionales de derechos humanos. Ade- 
cuación que, en los hechos, supuso una mejora progresiva en el reconocimiento del derecho a la seguridad social en este colectivo, durante este período.

Asimismo, se señaló que en el período 2016-2019 este panorama cambia abruptamente. El derecho a la seguridad social de las personas con discapacidad presenta retrocesos elocuentes tanto en las normativas como en los resultados de la política de pensiones por invalidez. Respecto a la regresividad normativa, a través de DNU se desarticula la institucionalidad pre-existente, cambiándola por una nueva. Se crea una Agencia descentralizada que generó una serie de normativas que fueron objetadas por el Poder Judicial por su carácter regresivo y contrario a la Convención sobre los Derechos de las Personas con Discapacidad. Se hace alusión a las Resoluciones 268/2018, 39/2019 y 44/2019 de la ANDI, que basadas en la sospecha de una gestión fraudulenta durante el período anterior, procuraron constituirse en los instrumentos legales para justificar la baja y suspensión de más de 150.000 prestaciones durante los años 2016 y 2017, a partir de la identificación de supuestas incompatibilidades. En cuanto a la regresividad en los resultados, al igual que en la gestión kirchnerista, el gobierno de Macri mantiene el Decreto 432 aplicado de manera taxativa, prescindiendo de la adecuación fáctica implementada en el período anterior, lo cual desencadenó la profusa suspensión y baja de prestaciones antes señalada. En otros términos, el macrismo tan solo garantizó la observancia de lo establecido en una norma anticonvencional.

Se considera que los evidentes retrocesos originados en el período 2016-2019, tuvieron como condición de posibilidad la escasa institucionalidad y el consecuente carácter endeble de los cambios que supuso la adecuación fáctica desarrollada en el período anterior. Dejando el escenario propicio para la embestida (esperable) de un gobierno de orientación neoliberal, que basó su gestión en el ajuste al gasto público social.

En ese marco, parece relevante destacar la importancia que adquiere la recepción de la normativa internacional de derechos humanos en la normativa interna de los Estados nacionales. Los estándares y principios del derecho internacional, debieran reflejarse incluso en el más pequeño acto administrativo del Estado.

En este caso, la vigencia y aplicación de una normativa interna manifiestamente incompatible con obligaciones asumidas a nivel internacional, generó consecuencias que afectaron directamente la calidad de vida y vulneraron el derecho a la seguridad social de miles de personas con discapacidad titulares de pensiones por invalidez. Pese a las advertencias del derecho internacional de derechos humanos y de las organizaciones de la sociedad civil de Argentina.

En tal sentido, la no derogación o modificación sustancial del Decreto 432 constituyó una omisión que supuso una violación del derecho a la seguridad social de estas personas, tanto en la gestión kirchnerista como en el gobierno macrista. Este último, además, adoptó una serie de medidas deliberadamente regresivas, incompatibles con las obligaciones básicas asumidas por el Estado nacional.

Por otro lado, es muy destacable la reacción organizada de las asociaciones de personas con discapacidad ante los retrocesos del período 2016-2019, reacción encabezada por REDI, organismo que presentó amparos colectivos que ganó casi en todas las instancias. Lo cual supuso un significativo precedente en cuanto al activismo y la acción colectiva del movimiento de las personas con discapacidad en la Argentina, y su disputa legal con el Estado Nacional representado por la ANDI. Se trata de una manifestación de ciudadanía activa que no presentaba antecedentes en este colectivo heterogéneo.

\section{REFERENCIAS BIBLIOGRÁFICAS}

AA.VV. (2017): Informe Alternativo. Situación de las Personas con Discapacidad en Argentina 2013/2017. Buenos Aires: CELS. Fecha de consulta: 18-11-2019. URL: https://www.ce/s.org.ar/web/publicaciones/situacion-de-laspersonas-con-discapacidad-en-la-argentina/

AA.VV. (2012): Informe Alternativo. Situación de la Discapacidad en Argentina - 2008/2012. Buenos Aires: CELS. Fecha de consulta: 20-11-2019. URL: http://www.redi.org.ar/Prensa/Comunicados/Informe-alternativo-al-comitesobre-los-derechos-de-las-personas-con-discapacidad-ONU.pdf

ACUÑA, C.; BULIT GOÑI, L. G. (2010): Políticas sobre la discapacidad en la Argentina. El desafío de hacer realidad los derechos. Buenos Aires: Siglo XXI Editores.

ARCIDIÁCONO, P. (2019): "La preocupación por la «trampa» y las confusiones en los expedientes judiciales sobre pensiones no contributivas", en Studia Politicæ, núm. 48, págs. 75-99. Facultad de Ciencia Política y Relaciones Internacionales de la Universidad Católica de Córdoba. Fecha de consulta: 20-12-2019. URL: http://revistas. bibdigital.ucc.edu.ar/index.php/SP/article/view/4548

BERTRANOU, F.; CASALÍ, P.; CETRÁNGOLO, O. (2019): ¿A mitad de camino entre Bismarck y Beveridge? La persistencia de los dilemas en el sistema previsional argentino. Informes Técnicos, núm. 9. Oficina de la OIT para 
GAPP. Nueva Época - N. ${ }^{\circ}$ 24, noviembre 2020 - ISSN: 1989-8991 - DOI: https://doi.org/10.24965/gapp.i24.10732 - [Págs. 86-105]

Transformaciones normativas recientes en el derecho a la seguridad social de las personas con discapacidad en Argentina Mauricio Mareño Sempertegui / Nora Britos

el Cono Sur de América Latina. Fecha de consulta: 18-12-2019. URL: https://www.ilo.org/wcmsp5/groups/public/--americas/---ro-lima/---sro-santiago/documents/publication/wcms_710670.pdf

BERTRANOU, F.; CETRÁNGOLO, O.; GRUSHKA, C.; CASANOV̄A, L. (2011): Encrucijadas en la seguridad social argentina: reformas, cobertura y desafíos para el sistema de pensiones. Buenos Aires: OIT y CEPAL.

BERTRANOU, F.; GRUSHKA, C. O. (2002): The non-contributory pension programme in Argentina: Assessing the impact on poverty reduction. ESS Paper, núm. 5. Social Security Policy and Development Branch International Labour Office.

BRITOS, N.; CARO, R. (2019): "Regresividad, remercantilización y dualización. Las reformas previsionales de la alianza Cambiemos", en NAZARENO, M.; SEGURA, M. S.; VÁZQUEZ, G. (eds.): Pasaron cosas. Política y políticas públicas en el gobierno de Cambiemos. Córdoba: Editorial Brujas, Facultad de Ciencias Sociales, Universidad Nacional de Córdoba.

BRITOS, N.; CARO, R. (2018): "Transformaciones regresivas en seguridad social. El caso de las pensiones no contributivas”, en Cuadernos de Coyuntura, Desigualdades, Eje Políticas públicas, núm. 2, págs. 31-36. Córdoba: Facultad de Ciencias Sociales, Universidad Nacional de Córdoba.

CASTEL, R. (1991): “La dinámica de los procesos de marginalización: de la vulnerabilidad a la exclusión”, en Revista Topía, vol. 1, núm. 2, págs. 18-27.

CENTRO DE ECONOMÍA POLÍTICA ARGENTINA (CEPA) (2017): PROpensión: los pensionados ajustados. Buenos Aires. Fecha de consulta: 15-07-2019. URL: https://www.centrocepa.com.ar/informes/161-propension-lospensionados-ajustados.html

CEPAL (2017): Base de datos de protección social no contributiva en América Latina y el Caribe. Fecha de consulta: 25-11-2019. URL: https://dds.cepal.org/bpsnc/programa?id=41

COMISIÓN DE DISCAPACIDAD DEL COLEGIO DE PROFESIONALES EN SERVICIO SOCIAL DE LA PROVINCIA DE CÓRDOBA (CPSSPC) (2018): Suspensión de Pensiones no Contributivas - 2018. Fecha de consulta: 25-12-2019. URL: http://cpsscba.org/confluenciasvirtual/?p=6389

COMITÉ DE DERECHOS ECONÓMICOS, SOCIALES Y CULTURALES (2018): Observaciones finales sobre el cuarto informe periódico de la Argentina E/C.12/ARG/CO/4, octubre de 2018. Fecha de consulta: 24-07-2019. URL: http://docstore.ohchr.org/SelfServices/FilesHandler.ashx?enc=4s/Q6QSmIBEDzFEovLCuW0fp9m5PoYHYL H3qkguQgxz\%2FAJxQn2BXMTHAKMg\%2Fr3LmfCC4TnS8uD0169hTPFbrLd3tWnOfNQfV\%2FwTfCNquztd145kC YGs\%2FA7pAutImBR3j

COMITÉ DE DERECHOS ECONÓMICOS, SOCIALES Y CULTURALES (2008): Observación General 19. EI derecho a la seguridad social. (Artículo 9). E/C.12/GC/19. Fecha de consulta: 27-12-2019. URL: https://www. acnur.org/fileadmin/Documentos/BDL/2012/8791.pdf

COMITÉ DE DERECHOS ECONÓMICOS, SOCIALES Y CULTURALES (1990): Observación General 3. La índole de las obligaciones de los Estados Partes (párrafo 1 del artículo 2 del Pacto). Fecha de consulta: 24-12-2019. URL: https://www.acnur.org/fileadmin/Documentos/BDL/2001/1452.pdf

COMITÉ DE EVALUACIÓN DEL SEGUIMIENTO DE LA CONVENCIÓN INTERAMERICANA PARA LA ELIMINACIÓN DE TODAS LAS FORMAS DE DISCRIMINACIÓN CONTRA LAS PERSONAS CON DISCAPACIDAD (2003): Informe Preliminar sobre la Situación de las Personas con Discapacidad en la Argentina. Fecha de consulta: 27-03-2020. URL: https://es.scribd.com/document/64275486/Informe-Preliminar-sobre-lasituacion-de-las-personas-con-discapacidad-en-la-Argentina

COMITÉ SOBRE LOS DERECHOS DE LAS PERSONAS CON DISCAPACIDAD (2018): Observación general núm. 6 sobre la igualdad y la no discriminación. GE.18-06662 (S). Fecha de consulta: 24-12-2019. URL: https:// tbinternet.ohchr.org/layouts/15/treatybodyexternal/Download.aspx?symbolno=CRPD/C/GC/6\&Lang=en

COMITÉ SOBRE LOS DERECHOS DE LAS PERSONAS CON DISCAPACIDAD (2018): Observación general núm. 7 sobre la participación de las personas con discapacidad, incluidos los niños y las niñas con discapacidad, a través de las organizaciones que las representan, en la aplicación y el seguimiento de la Convención. GE.1818970 (S). Fecha de consulta: 28-12-2019. URL: https://tbinternet.ohchr.org/_layouts/15/treatybodyexternal/ Download.aspx?symbolno=CRPD/C/GC/7\&Lang=en

CORSIGLIA MURA, L. (2018): "Ciudadanías en proceso de ajuste: Un recorrido a través de las actuales políticas previsionales", en X Jornadas de Sociología de la UNLP, 5 al 7 de diciembre de 2018, Ensenada, La Plata (Actas). Ensenada: Universidad Nacional de La Plata. Facultad de Humanidades y Ciencias de la Educación. Departamento de Sociología. Fecha de consulta: 30-01-2020. URL: http://www.memoria.fahce.unlp.edu.ar/trab_ eventos/ev.11445/ev.11445.pdf

COURTIS, C. (2006): "La prohibición de regresividad en materia de derechos sociales: apuntes introductorios", en COURTIS, C. (comp.): Ni un paso atrás, págs. 3-52. Buenos Aires: Editores del Puerto.

DANANI, C. (2016): "Las políticas públicas del área de desarrollo social durante los gobiernos de Néstor Kirchner y Cristina Fernández", en Análisis, núm. 12. Berlín: Fundación Friedrich Ebert Stiftung. Fecha de consulta: 19-122019. URL: https://library.fes.de/pdf-files/bueros/argentinien/12771.pdf

DVOSKIN, N. (2016): "La reforma previsional del macrismo: el retorno de la estigmatización en la política social”, en Revista: Épocas, págs. 1-11. Fecha de consulta: 30-01-2020. URL: https://ri.conicet.gov.ar/bitstream/ handle/11336/22229/CONICET_Digital_Nro.24889\%20\%281\%29.pdf?sequence=2\&isAllowed=y 
GAPP. Nueva Época - N. ${ }^{\circ}$ 24, noviembre 2020 - ISSN: 1989-8991 - DOI: https://doi.org/10.24965/gapp.i24.10732 - [Págs. 86-105]

Transformaciones normativas recientes en el derecho a la seguridad social de las personas con discapacidad en Argentina

Mauricio Mareño Sempertegui / Nora Britos

GOLBERT, L.; ROCA, E. (2010): "De la Sociedad de Beneficencia a los derechos sociales", en Revista de Trabajo, año 6, núm. 8, enero/julio. Buenos Aires.

GRASSI, E.; HINTZE, S. (coord.) (2018): Tramas de la desigualdad. Las políticas y el bienestar en disputa. Buenos Aires: Prometeo Libros. 1. ${ }^{a}$ ed. ISBN: 978-987-574-959-7.

FINDLING, L.; VENTURIELLO, M. P.; CIRINO, E. (2018): "Restringiendo derechos para las personas mayores y con discapacidad. Un panorama de las políticas de previsión social y salud en el marco de un nuevo Estado neoliberal", en Revista de la Carrera de Sociología, vol. 8, núm. 8, págs. 56-89. Fecha de consulta: 19-12-2019. URL: https://publicaciones.sociales.uba.ar/index.php/entramadosyperspectivas/article/view/3036/2624

FOUCAULT, M. (1976): "La crisis de la medicina o la crisis de la antimedicina", en Revista Educación Médica y Salud (OPS), vol. 10, núm. 2, págs. 17-35.

INSTITUTO NACIONAL DE ESTADÍSTICAS Y CENSOS (INDEC) (2014): Censo Nacional de Población, Hogares y Viviendas 2010. Censo del Bicentenario. Población con dificultad o limitación permanente. Serie C. Buenos Aires. $1 .^{\mathrm{a}} \mathrm{ed}$

INSTITUTO NACIONAL DE ESTADÍSTICAS Y CENSOS (INDEC) (2012): Censo Nacional de Población, Hogares y Viviendas 2010. Censo del Bicentenario: resultados definitivos. Serie B, núm. 2. Buenos Aires. 1. ${ }^{a}$ ed.

INSTITUTO NACIONAL DE ESTADÍSTICAS Y CENSOS (INDEC) (2006): Principales resultados de la primera encuesta nacional de personas con discapacidad (ENDI) complementaria del censo 2001. Serie Estudios, núm. 42. Buenos Aires. $1 .^{\mathrm{a}}$ ed.

HOPP, M. V.; LIJTERMAN, E. (2019): "Trabajo, derechos sociales y protección social en Argentina de la reconstrucción neoliberal”, en Revista Katálysis, vol. 22, núm. 1, págs. 66-79. Fecha de consulta: 28-12-2019. URL: $h t t p: / / w w w . s c i e l o . b r / p d f / r k / v 22 n 1 / 1982-0259-r k-22-01-66 . p d f$

LOMBARDÍA, M. L.; RODRÍGUEZ, K. (2015): La experiencia argentina en políticas de transferencias monetarias durante la última década. Documento de Trabajo, núm. 7. Buenos Aires: Secretaría de Política Económica y Planificación del Desarrollo, Subsecretaría de Programación Macroeconómica. Fecha de consulta: 19-12-2019. URL: https://www.economia.gob.ar/peconomica/basehome/DT_07\%20la\%20experiencia_03.pdf

MALLARDI, M. W.; FERNÁNDEZ, E. N. (2019): La protección social en la Argentina: àlgunos elementos para caracterizar las Pensiones No Contributivas Asistenciales. Documentos de Trabajo CIEPP, núm. 103. Diciembre, págs. 1-38. Centro Interdisciplinario para el Estudio de Políticas Públicas. Fecha de consulta: 10-07-2019. URL: http://ciepp.org.ar/images/ciepp/docstrabajo/Documento_103.pdf

MARTÍNEZ, L. (2018): “¿Qué pasa con las pensiones por discapacidad?”, en Chequeado. Explicadores. URL: https:// chequeado.com/el-explicador/que-pasa-con-las-pensiones-por-discapacidad/

MINISTERIO DE SALUD Y DESARROLLO SOCIAL (2018): Boletín Estadístico de la seguridad social. Tercer Trimestre 2018. Secretaría de Seguridad Social. Dirección de Programación Económica. Fecha de consulta: 2812-2019. URL: https://www.argentina.gob.ar/sites/default/files/bess_3ertrim_2018.pdf

MORO, J.; POTENZA DAL MASETTO, F. (2010): "Análisis de los organismos gubernamentales y estatales", en ACUÑNA, C.; BULIT GOÑI, L. (comps.): Políticas sobre la discapacidad en la Argentina: el desafío de hacer realidad los derechos, págs. 191-253. Buenos Aires: Siglo XXI Editores.

ORGANIZACIÓN INTERNACIONAL DEL TRABAJO (2002): Seguridad social: un nuevo consenso. Ginebra: OIT.

ORGANIZACIÓN DE NACIONES UNIDAS (2006): Convención Internacional sobre los derechos de las personas con discapacidad. Asamblea General de Naciones Unidas. Fecha de consulta: 27-12-2019. URL: https://www.un.org/ esa/socdev/enable/documents/tccconvs.pdf

ORGANIZACIÓN IBEROAMERICANA DE SEGURIDAD SOCIAL (OISS) (2014): Medidas para la promoción del empleo de personas con discapacidad en Iberoamérica. Madrid: Secretaría General de la OISS. Fecha de consulta: 12-11-2019. URL: https://oiss.org/wp-content/uploads/2000/01/Oiss_Estudio_sobre_medidas_ promocion_de_empleo-2.pdf

RALS; CELS; REDI (2003): La Situación de las Personas con Discapacidad en Argentina. Buenos Aires: Centro de Estudios Legales y Sociales. Fecha de consulta: 17-11-2019. URL: https://www.cels.org.ar/common/documentos/ cerd_personas_discapacidad.pdf

REATI, E. (2019): "Pensiones por discapacidad. El ajuste más cruel", en Instituto Patria. Fecha de consulta: 23-072019. URL: https://www.institutopatria.com.ar/pensiones-por-discapacidad-el-ajuste-mas-cruel/

RED POR LOS DERECHOS DE LAS PERSONAS CON DISCAPACIDAD (REDI) (2019): Suspensión de los Efectos. Vista de Expediente. Acceso a la Información Pública. Recurso de Alzada. Nulidad. Recurso de alzada contra las Resoluciones 39 y 44 dictadas por la Agencia Nacional de Discapacidad y publicadas en el Boletín Oficial de la República Argentina en fechas 4 y 8 de febrero de 2019. Buenos Aires, 20 de febrero de 2019. URL: http://www.redi.org.ar/Prensa/Comunicados/2019/19-02-20_suspension-de-las-resoluciones-que-exigen-nuevoscontroles nota2.pdf

ROFMAN, R.; APELLA, I.; VEZZA, E. (eds.) (2013): Más allá de las Pensiones Contributivas. Catorce experiencias en América Latina. Buenos Aires: Banco Mundial. 1. ${ }^{a}$ ed. Fecha de consulta: 16-12-2019. URL: http://documentos. bancomundial.org/curated/es/624841468047055585/pdf/827240WP0P12960sionesOcontributivas.pdf

SORGI, M.; CALDERÓN, J. (2017): "La pensión no contributiva por invalidez bajo el enfoque de derechos humanos", en El Derecho: Diario de Doctrina y Jurisprudencia, núm. 14.167, Año IV, págs. 1-5. Buenos Aires. 


\section{LEYES, DECRETOS, SENTENCIAS Y RESOLUCIONES}

AGENCIA NACIONAL DE DISCAPACIDAD (2018): Resolución 268/2018. Circuito Administrativo de Notificación de Incompatibilidades con el Decreto 432/97 - Aprobación. Buenos Aires, 20 de septiembre de 2018. URL: http:// servicios.infoleg.gob.ar/infolegInternet/anexos/310000-314999/314680/norma.htm

AGENCIA NACIONAL DE DISCAPACIDAD (2019): Resolución 39/2019. Circuito de Confección del Certificado Médico Oficial - Apruébase. Buenos Aires, 31 de enero de 2019. URL: http://servicios.infoleg.gob.ar/ infoleginternet/anexos/315000-319999/319484/norma.htm

AGENCIA NACIONAL DE DISCAPACIDAD (2019): Resolución 44/2019. Circuito Administrativo de Renovación de Certificados - Apruébase. Buenos Aires, 06 de febrero de 2019. URL: http://servicios.infoleg.gob.ar/infoleglnternet/ anexos/315000-319999/319704/norma.htm

HONORABLE CONGRESO DE LA NACIÓN ARGENTINA (1948): Ley 13.478. Suplemento variable sobre el haber de las Jubilaciones. Buenos Aires, 15 de octubre de 1948. URL: http://servicios.infoleg.gob.ar/infoleglnternet/ anexos/30000-34999/32032/norma.htm

PODER EJECUTIVO NACIONAL (P.E.N.) (1970): Ley 18.910. Régimen de pensiones a la vejez y por invalidez. Modificación de la Ley 13.478. Buenos Aires, 30 de diciembre de 1970. URL: http://servicios.infoleg.gob.ar/ infolegInternet/anexos/155000-159999/158845/norma.htm

PODER EJECUTIVO NACIONAL (P.E.N.) (2017): Decreto de Necesidad y Urgencia 698/2017. Agencia Nacional de Discapacidad e Instituto Nacional de las Mujeres (Creación). Buenos Aires, 05 de septiembre de 2017. URL: http:// servicios.infoleg.gob.ar/infolegInternet/anexos/275000-279999/279040/norma.htm

PODER EJECUTIVO NACIONAL (P.E.N.) (2018): Decreto de Necesidad y Urgencia 95/2018. Ley de Ministros (Modificación). Buenos Aires, 01 de febrero de 2018. URL: http://servicios.infoleg.gob.ar/infoleglnternet/ anexos/305000-309999/306532/norma.htm

PODER EJECUTIVO NACIONAL (P.E.N.) (1997): Decreto Reglamentario 432/1997. Pensiones a la Vejez y por Invalidez - Reglamentaciones. Buenos Aires, 15 de mayo de 1997. URL: http://servicios.infoleg.gob.ar/ infolegInternet/anexos/40000-44999/43325/norma.htm

PODER JUDICIAL DE LA NACIÓN DE ARGENTINA. CÁMARA FEDERAL DE APELACIONES DE LA SEGURIDAD SOCIAL - SALA 2 (2019): Sentencia definitiva. Expediente CAF 039031/2017/CA002. Autos: ASOCIACIÓN REDI Y OTROS C/ EN-M DESARROLLO SOCIAL S/AMPAROS Y SUMARISIMOS. Buenos Aires, 15 de marzo de 2019. URL: http://www.redi.org.ar/Pensiones/19_03_18_sentencia_definitiva_de_segundas_ instancia.pdf

PODER JUDICIAL DE LA NACIÓN DE ARGENTINA. CÁMARA FEDERAL DE LA SEGURIDAD SOCIAL - SALA 2 (2019): Sentencia Definitiva. Expediente No 39031/2017. Autos: ASOCIACIÓN REDI Y OTROS c/ EN-M DESARROLLO SOCIAL S/AMPAROS Y SUMARISIMOS. Buenos Aires, 15 de marzo de 2019. URL: http://www. redi.org.ar/Pensiones/19_03_18_sentencia_definitiva_de_segundas_instancia.pdf

PODER JUDICIAL DE LA NĀCIÓN DE ARGENTINA. CÁMĀRA FEDERAL DE LA SEGURIDAD SOCIAL - SALA 2 (2019): Resolución Judicial. Causa No 39031/2017. Autos: ASOCIACIÓN REDI Y OTROS c/ EN-M DESARROLLO SOCIAL S/AMPAROS Y SUMARISIMOS. Buenos Aires, 04 de abril de 2019. 